\title{
Editorial
}

\section{Sosquua. Revista Especializada en Gastronomía. Una nueva alternativa de comunicación investigativa en el campo de la gastronomía colombiana}

"Los investigadores alimentamos el instinto de saber; somos operarios del patrimonio intelectual de la humanidad"

José María Martín Senovilla (2014)

El gastrónomo, dentro de la formación profesional colombiana en la actualidad, se debe enfrentar a poder reconocer e identificar las diversas costumbres y tradiciones que enmarca la sociedad. Esto lo hace mediante procesos de investigación que ayuden a la generación de una identidad gastronómica colombiana.

En este primer número, celebramos el nacimiento de nuestra Sosquua. Revista Especializada en Gastronomía que busca ser una plataforma de difusión de las diversas indagaciones realizadas en el marco de la investigación y la formación. Con la ayuda de nuestro grupo de investigación del Patrimonio Cultural y Gastronómico de Colombia, los docentes, los estudiantes y la comunidad científica buscamos ser agentes de cambio encaminados a salvaguardar las tradiciones de las regiones de Colombia. En esta medida, reflexionamos sobre la difusión del patrimonio inmaterial desde la recetas autóctonas, además de la labor de los portadores de tradición quienes son los encargados de custodiar el acervo cultural de nuestros antepasados.

Mediante la divulgación de este espacio, queremos generar un canal de comunicación entre la comunidad científica y académica. Ellos serán los encargados de establecer la importancia de identificar las principa- 
les técnicas ancestrales y los elementos culturales que componen la sociedad colombiana. Como consecuencia, generarán espacios de aprendizaje donde los conceptos que se adquieran dentro del aula de clase puedan verse reflejados en la práctica y analizados desde los casos de estudios que se desenvuelven en el sector gastronómico.

Como un compromiso adquirido, el gastrónomo profesional colombiano se encuentra orientado a generar nuevas propuestas que ayuden a difundir los conocimientos y saberes. Lo anterior permite enlazar su responsabilidad social como garante de nuevas experiencias que fortalezcan el reconocimiento autóctono de las regiones. A nivel educativo, el especialista de esta profesión debe ser un agente dinamizador de espacios de clase experimental; con un enfoque dirigido a potencializar competencias que brinden soluciones integrales a la falta del conocimiento de ingredientes, entornos culturales y elementos sociales que ayuden en el reconocimiento de una identidad nacional en las preparaciones culinarias.

Como proceso académico, Sosquua. Revista Especializada en Gastronomía quiere convertirse en fuente de consulta a nivel científico. Los debates generados dentro de este espacio son procesos que fomenten la cultura, la identidad y el arraigo de nuestras tradiciones a nivel local, nacional e internacional. Además, espera contar con la construcción conjunta de Instituciones de Educación Superior y grupos de investigación, quienes tienen un espacio para la publicación de sus indagaciones.

Los invitamos a que sigan participando de esta su revista, un lugar donde la ideas se complementan a partir de experiencias y conocimientos.

Royer Yesid Gutiérrez Quecano

Editor

Grupo de investigación Patrimonio Cultural Gastronómico de Colombia

Fundación Universitaria San Mateo 


\section{Primera Edición}

Sosquua. Revista Especializada en Gastronomía, nace con la presente edición electrónica y como proyecto editorial de la Dirección de Investigación, junto con la Editorial de la Fundación Universitaria San Mateo y la Facultad de Ciencias Administrativas y Afines.

Sosquua es una publicación sometida a revisión anónima de pares académicos. Promueve el debate en torno a la gastronomía, al desarrollo de productos, al emprendimiento gastronómico y al rescate del patrimonio cultural gastronómico. Así mismo, la revista acepta propuestas que propendan por la relación de la disciplina con otras áreas del conocimiento. Sosquua nace para editarse cada seis meses a través de la plataforma Open Journal Systems, y proporcionar acceso libre e inmediato a cada edición electrónica.

Este número cuenta con dos secciones. La primera corresponde a artículos resultados de investigación. La segunda parte ofrece información sobre publicaciones recientes de interés disciplinar.

La revista cuenta con el respaldo institucional de la Fundación Universitaria San Mateo y el Grupo de Investigación Patrimonio Cultural y Gastronómico de Colombia, Categoría B en Colciencias, adscrito a la Facultad de Ciencias Administrativas y Afines.

En la presente edición se tuvo apoyo de pares académicos de distintas universidades que elaboraron sus conceptos académicos ad honorem. Expresamos nuestro agradecimiento público a todos ellos por su importante y valiosa colaboración con esta edición.

Coordinación de publicaciones 